\title{
Study of Biology and Bioclimatology Applied of Apricot (Prunus Armeniaca L.): to Increase the Economy and Maintaining Food Security in Palestine
}

\author{
*Jehad M. H. Ighbareyeh, A. Cano-Ortiz, E. Cano Carmona, Mohammed M. H. \\ Ighbareyeh, Asmaa A. A. Suliemieh
}

Department of Animal and Plant Biology and Ecology, Faculty of Experimental Sciences, University of Jaen, Jaen, Spain

*jehadighbareyeh@hotmail.com

\begin{abstract}
Apricot (Prunus armeniaca L.) is one of the most important export crops in Palestine and Palestine is the leading fresh and dried apricot producer all over the world. We analyzed the mean annual temperature and precipitation using data from tenth weathers stations from the Palestine Meteorological Department, recorded in the period from 1993-2008 (15 years), with the same years plant production (rainfed) from the Palestinian Central Bureau of Statistics (PCBS). Statistical tests included a bioclimatic analysis of Palestinian meteorological stations for the period previous by using bioclimatic classification of the Earth of Rivas Martinez Salvador, with regard to simple continentality index, compensated thermicity index, annual ombrothermic index, water deficit and soil water reserve. In concluded, when we applied a principal component analysis (PCA), observed that the Ramallah, Salfit, Nablus, Hebron, Bethlehem and Jerusalem areas were affected by the factors simple thermicity index, precipitation, and soil water reserve, excepted Hebron, Bethlehem and Jerusalem were affected by bioclimate factor as annual ombrothermic index, with a proportion of the variance explained by axes $1(44.55 \%)$ and Jenin and Tubas areas were affected by the bioclimate factors as an annual ombrothermic index. We indicated that in the inframediterranean to mesomediterranean environments, the optimum for the production of apricot is achieved with value of annual ombrothermic index more than 2.5, simple continentality index value between 14-22, compensated thermicity index value between 250-450, the temperature between 20-25 C, with annual rainfall between 300-900 millimeters, and with the dry to humid of ombrotype.
\end{abstract}

Keywords: Palestine, bioclimate, biology, economic, ombrotype.

\section{INTRODUCTION}

An apricot tree is from the tree species Prunusarmeniaca L, but the species Prunusbrigantina, Prunusmandshurica, Prunusmume, and Prunussibirica are closely related, have similar fruit, and are also called apricots [1].This tree takes its name from Armenia, province of Asia, where it is native, and whence it was brought to Europe [2], an archaeological excavation at Garni in Armenia found apricot seeds in an Eneolithic-era site [3], and three centers of apricot origin were proposed by Vavilov [4]:north eastern, central and western China, central Asian mountains and near-eastern center. Apricot was introduced into the Mediterranean Basin through two different ways. The first one was through the Middle-East allowing the identification of the Irano-Caucasian group [5], and the second was through the Central Europe [6]. Four apricot cultivar groups named (Diversification, Geographically Adaptable, Continental Europe and Mediterranean Basin) were identified by Hagen et al. [7]; these groups displayed a gradient of decreasing genetic diversity of varieties from east to south-west. However, the climate of Mediterranean region which have semiarid, having hot summers and mild-winters can be occurred rarely frost damage [8].Apricot culture is greatly restricted by climatic conditions, especially related to chill accumulation in several growing areas, with a significant influence on productivity $[9,10]$.

Apricot (Prunus armeniaca L.) is a very popular commercial and nutritional stone fruit crop that is cultivated widely under temperate world regions, especially in Mediterranean countries and areas with similar conditions, due to its high delicious edible fruit and potential to fetch premium prices at market. Data from FAOSTAT [11] revealed that $>3.8$ million tons of apricots were produced in the world in 2011. 
Palestine has a Mediterranean climate characterized by long, hot, dry summers and short, cool, rainy winters, as modified locally by altitude and latitude. Like many other developing countries, Palestine has an important agricultural sector, which has been considered the backbone of its economy; it's the most suitable ecological conditions for growing table apricot. Apricot planting in Palestinian areas has increased rapidly due to the comparative advantage of earliness of harvest. The apricot trees of Palestine are grown in mountainous inland areas and the most important varieties are wild (Armeniaca vulgaris), Hamwi (Mestikawy), Al-Qaisi, Tadmory, Lozi and Ajmi.

Recent studies [12-26] have highlighted the influence of bioclimatology on plant yield; however this is the first time the bioclimatic characterization of the different varieties has been under taken. Palestine is belonging to the inframediterranean to mesomediterranean of bioclimatic belts; and arid, semiarid, dry, sub-humid and humid of ombrotype [12-15].

Aims study the effect of biology, bioclimatology and climatology on Apricot (Prunus armeniaca L.) to establish the variables that had the greatest influence on plant production to increase the economy and maintaining food security in the region of Palestine, because apricots are one of the most important fruit in Palestine.

\section{Materials And Methods}

\subsection{Study Area}

Palestine is located between longitudes $34^{\circ} 15^{\prime}$ and $35^{\circ} 40^{\prime}$ east and between latitudes $29^{\circ} 30^{\prime}$ and $33^{\circ} 15^{\prime}$ north. The geographic location of Palestine plays a major role in affecting the features of its climate and the climate diversity between the southern and northern parts.

\subsection{Data Analysis and Collections}

Palestine is famous in cultivation of apricots, especially in the mountains of Hebron and other areas. Data were used from the meteorological stations in Palestine (Table 1) and (Fig 1). Mean temperature, precipitation data from ten stations with records from 1993 to 2008 (15 years) and for the same years in plant production (rainfed) from the Palestinian Central Bureau of Statistics (PCBS), have been analyzed in this study. A bioclimatic and climate analyses have been made of the data from the Palestinian meteorological stations of the same years ago, so we are dependent in the bioclimatic analysis about used temperature and rainfall amount of data for Palestinian Meteorological Stations, elaboration the diagram bioclimatic according the professor Rivas Martinez Salvador in 1996 [27-30]. An analysis was made of the independent and independent variables, independent variable consist of biocliamte factors as compensated thermicity index (It/Itc), annual ombrothermic index (Io), simple continentality index (Ic), and climate factors as mean monthly temperature $(\mathrm{T})$, precipitation $(\mathrm{P})$, soil water reserve $(\mathrm{R})$ and water dificit $(\mathrm{Df})$, while dependent variable is apricot production (table 1).

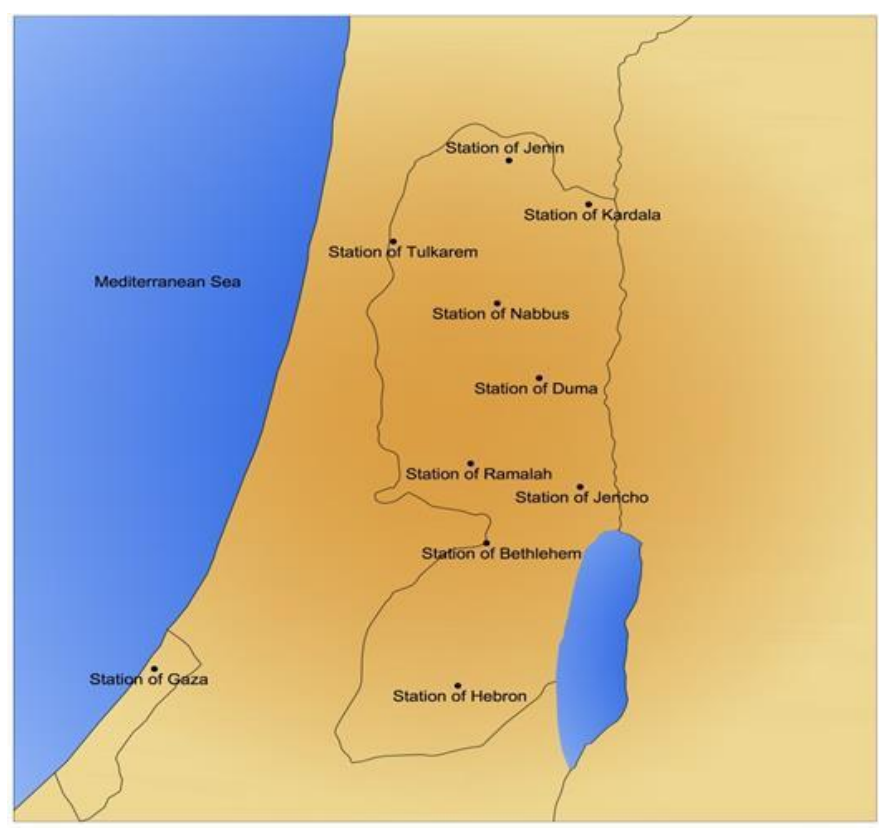

Fig1. Location of the Meteorological Palestinian Stations 
Study of Biology and Bioclimatology Applied of Apricot (Prunus Armeniaca L.): to Increase the Economy and Maintaining Food Security in Palestine

Table1. Independents Variables (Climate and Bioclimate Factors) and Dependent Factors (Plant Production) from 1993-2008

\begin{tabular}{|l|l|l|l|l|l|l|l|l|}
\hline Site & T & $\mathbf{P}$ & Df & $\mathbf{R}$ & It/Itc & Ic & Io & Production of Apricot \\
\hline Jenin & 20.4 & 490 & 780 & 420 & 450 & 17.4 & 1.89 & 471 \\
\hline Tulkarem & 22.4 & 601 & 830 & 445 & 480 & 17.2 & 2.44 & 170 \\
\hline Nablus & 17.9 & 683 & 614 & 474 & 350 & 19.1 & 3.21 & 152.5 \\
\hline Salfit & 22 & 600 & 700 & 480 & 466 & 17.6 & 2.63 & 449 \\
\hline Qalqilia & 20.1 & 611 & 612 & 449 & 480 & 17.9 & 2.51 & 135 \\
\hline Tubas & 19.2 & 405 & 730 & 444 & 490 & 16.9 & 2.78 & 644 \\
\hline Ramallah & 17.1 & 614 & 590 & 462 & 311 & 17.8 & 3.19 & 152.33 \\
\hline Jerusalem & 18.8 & 549 & 580 & 413 & 390 & 17.4 & 2.33 & 317 \\
\hline Bethlehem & 17.9 & 548 & 600 & 420 & 400 & 16.18 & 2.89 & 360 \\
\hline Hebron & 16.6 & 595 & 583 & 417 & 297 & 18.11 & 3.19 & 409 \\
\hline
\end{tabular}

P: Production, Yield: Kg. dunum.

Nevertheless, we applied the principal component (PCA), correlation matrix (Pearson n-1) and correspondence analysis (CA).These statistical analyses were done using the XLSTAT software. The goal of PCA is to decompose a data table with correlated measurements into a new set of uncorrelated variables. The results of the analysis are presented with graphs plotting the projections of the units onto the components, and the loadings of the variables. Correlation between variables was evaluated using Pearson's correlation coefficient [31].

\section{RESUltS AND DisCUSSION}

\subsection{Principal Component Analysis}

In this study, we used the bioclimatic classification of earth to Salvador Rivas-Martinez to analyses of the climate factors and bioclimatic parameters (independent variables). After application of the Shapiro-Wilk normality test [32-35], the p-value obtained from the variables studied tended to be below 0.05 , a conventionally accepted value.

Principal component analysis (PCA) is a useful statistical technique that has found application in fields such as face recognition and image compression, and is a common technique for finding patterns in data of high dimension. PCA correspondence analysis creates orthogonal components and, for each item in a table, a set of scores (sometimes called factor scores). PCA was used to help identify the variables different, using factor extraction with an eigenvalue $>1$ after varimax rotation. The results of PCA, including the factor loadings with a varimax rotation as well as the eigenvalues, are tabulated in (Table 2). Eight of the eigenvalues were found to be $>1$ and the total variance for the two factors isabout $44.552 \%$. Factor 1 was dominated by temperature, water deficit and compensated thermicity index, and accounts for $44.552 \%$ of the totalvariance and cumulative \% (Fig. 2). That means domination may be caused by the effect of the variables (dependent and independent factors) on plant yield and growth. Factor 2 is highly dominated by all climate and bioclimate factors except of Io is negatively (-0.058), and accounts for $29.482 \%$ of the total variance. This factor represents, effect, and interesting of all climatology and bioclimatology factors on biology, production, development and sustainability of plant. Factor 3 is dominated by all climate and bioclimate factors except of $\mathrm{T}$ and $\mathrm{P}$, and accounts for $12.355 \%$ of the total variance. Factor 4 is dominated by T, Df (0.337) and Ic (0.722), and accounts for $6.657 \%$ of the total variance. Factor 5 is height dominated by Df, Io, P and T conductivity, and accounts for $4.221 \%$ of the total variance. Factor 6 is dominated by $\mathrm{T}$ and $\mathrm{P}$, while the factors of Df, Ic, It/Itc, Io and R were negatively, and accounts for $2.233 \%$ of the total variance. Factor 7 is dominated by $\mathrm{P}$, and Df as climate factors, and accounts for $0.409 \%$ of the total variance. Factor 8 is dominated by P, Io, Ic, and It/Itc conductivity, and accounts for $0.090 \%$ of the total variance, generally, abiotic factors effected on the productivity, sustainability, and stage of growth and development of plant and its relationship to increase economic in Palestine, addition to, these environments factors were effected on plant biology and other biological resource [12-14].

We observed through analysis and study that temperature effect on plant production as f 2 , f 2 , f 5 , f6 and $\mathrm{f} 7$, therefore, apricot trees are affected by weather conditions, especially during the flowering period and modern decade as rising temperatures in the period after the contract and the growth of fruits adversely affect the yield and fruit specifications. In contrast, and the lack of cold during the fall and winter cause dormancy period is not complete and therefore lead to the delay in the open floral 
buds and vegetative, and in a short period of dormancy apricot trees, addition to suitable cultivation of apricots in cold weather and the climate of the Mediterranean, but that his best environment is dry environment. The increase in relative humidity during this period to help increase the spread of fungal diseases, particularly whiteness diseases that cause the deterioration of fruit quality. In the other side, wild apricot pollination is carried out by bees and insects, which are attracted to the abundant blossoms produced during March and April [36, 37].

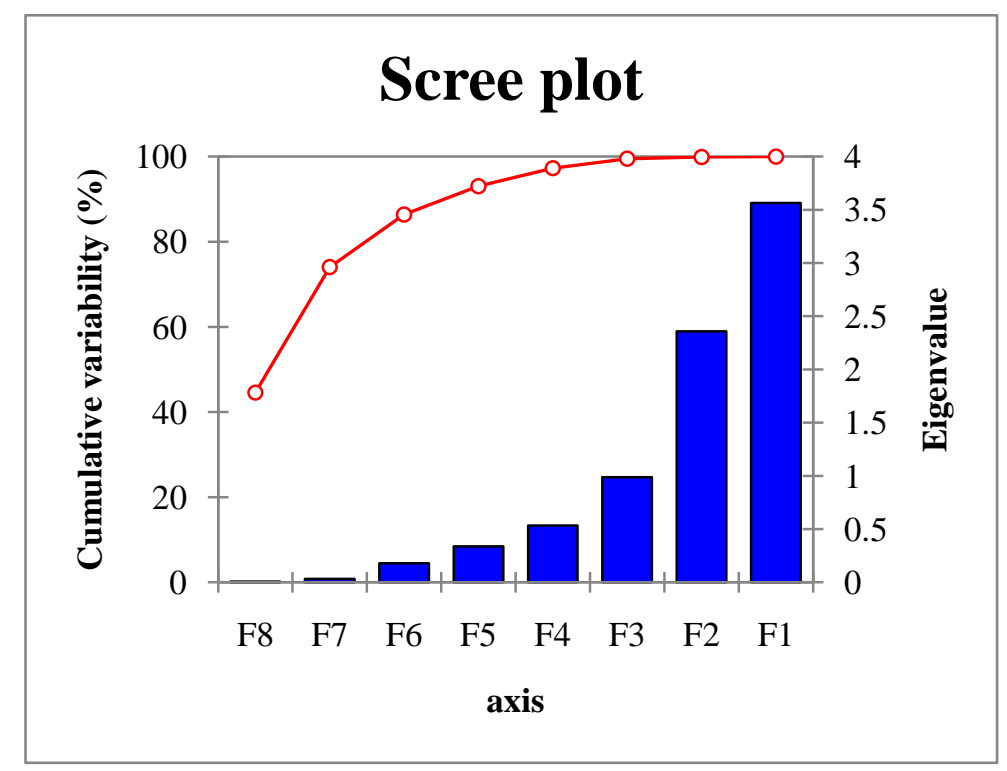

Fig.2. Factors of the Cumulative and Eigenvalue PCA of Variables Data (Dependent and Independent Factors)

Nevertheless, when we applied a principal component analysis (PCA), observed that the Ramallah, Salfit, Nablus, Hebron, Bethlehem and Jerusalem areas types plots are located at the right of axis 2, and affected by the factors Ic, P and R, excepted Hebron, Bethlehem and Jerusalem were affected by bioclimate factor as annual ombrothermic index, with a proportion of the variance explained by axes 1 $(44.55 \%)$ (Fig.3). Jenin and Tubas areas plots are located at the left of the axes 1 and more affected by the bioclimate factors as anannual ombrothermic index; while, Tulkarem and Qalqilia were affected by soil water reserve, in soils like these, fertilization can cause a numerous management problems, especially by changing soil $\mathrm{pH}$ which affects, in general, the availability of plant nutrients, and there by plant growth, productivity and fruit quality [38]; compensated thermicity index; andmean monthly temperature, we indicate that apricot of Palestine can be adapted to climate in this region, with cold winters to allow a proper dormancy and a dry climate is good for fruit maturation. The tree is slightly more cold-hardy than the peach, tolerating winter temperatures as cold as $-30{ }^{\circ} \mathrm{C}\left(-22^{\circ} \mathrm{F}\right)$. A limiting factor in apricot culture is spring frosts: They tend to flower very early, meaning spring frost can kill the flowers. Furthermore, apricotis adapted in dry to humid regions which are characterized by temperate summers with temperature between $15-30^{\circ} \mathrm{C}$, which had to obtain high quality of production,

Table2. Factors of Eigenvectors and Eigenvalue of the PCA and Variables Data (Dependent and Independent Factors)

\begin{tabular}{|l|l|l|l|l|l|l|l|l|}
\hline Variables & \multicolumn{1}{|c|}{ F1 } & F2 & \multicolumn{1}{|c|}{ F3 } & F4 & F5 & F6 & F7 & \multicolumn{1}{c|}{ F8 } \\
\hline T & 0.381 & 0.428 & -0.059 & -0.050 & 0.043 & 0.433 & 0.568 & -0.392 \\
\hline P & -0.369 & 0.416 & -0.223 & -0.116 & 0.187 & 0.448 & -0.023 & 0.626 \\
\hline Df & 0.416 & 0.225 & 0.100 & 0.337 & 0.737 & -0.231 & -0.197 & 0.132 \\
\hline $\mathbf{R}$ & -0.043 & 0.515 & 0.579 & -0.132 & -0.219 & 0.106 & -0.524 & -0.216 \\
\hline Itc & 0.452 & 0.235 & 0.083 & -0.317 & -0.364 & -0.439 & 0.216 & 0.511 \\
\hline Ic & -0.347 & 0.320 & 0.113 & 0.722 & -0.254 & -0.272 & 0.320 & 0.039 \\
\hline Io & -0.401 & -0.058 & 0.521 & -0.386 & 0.406 & -0.220 & 0.448 & -0.032 \\
\hline Production of apricots & 0.242 & -0.409 & 0.558 & 0.286 & -0.100 & 0.481 & 0.115 & 0.355 \\
\hline Eigenvalue & 3.564 & 2.359 & 0.988 & 0.533 & 0.338 & 0.179 & 0.033 & 0.007 \\
\hline Variance \% & 44.552 & 29.482 & 12.355 & 6.657 & 4.221 & 2.233 & 0.409 & 0.090 \\
\hline Cumulative \% & 44.552 & 74.034 & 86.389 & 93.046 & 97.267 & 99.501 & 99.910 & 100.000 \\
\hline
\end{tabular}




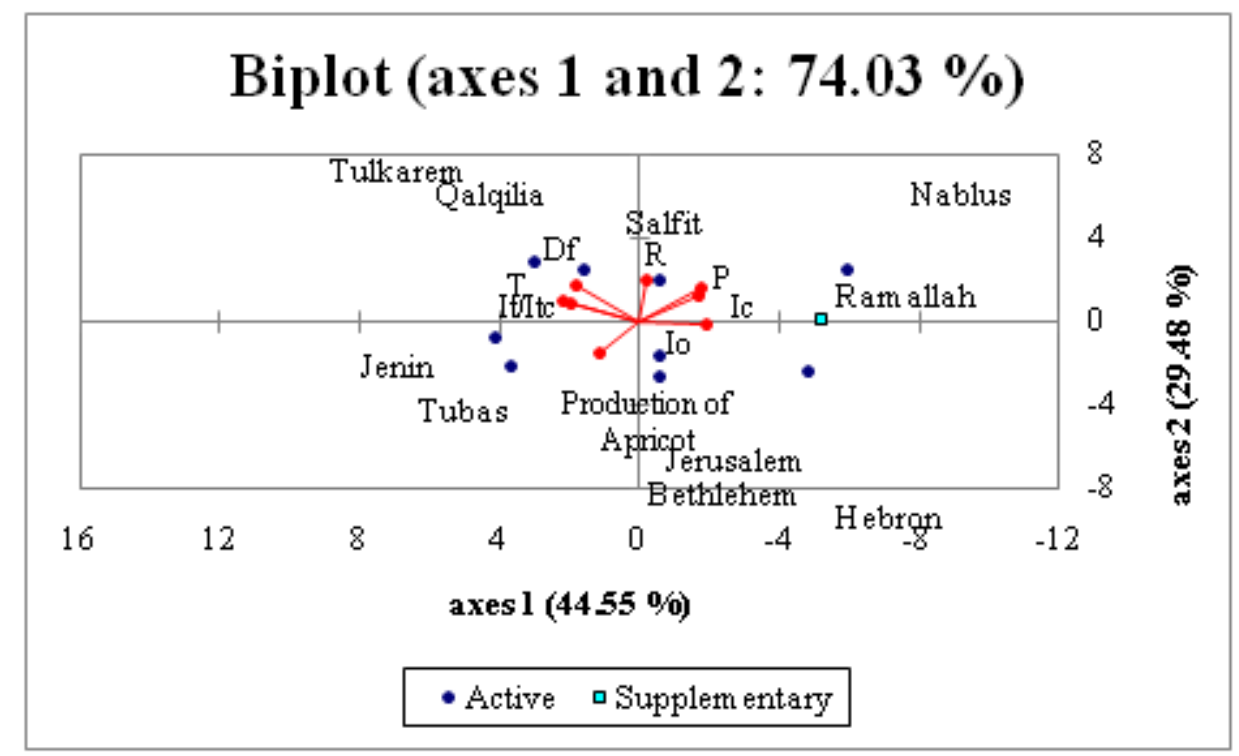

Fig3. Graphic of Principal Component Analysis between Independent and Independent Variables

\subsection{Correlation Matrix (Pearson N-1)}

Table3. Pearson's Correlation Matrix between the Different Variables

\begin{tabular}{|c|l|l|l|l|l|l|l|l|}
\hline Variables & T & $\mathbf{P}$ & $\mathbf{D f}$ & $\mathbf{R}$ & Itc & Ic & Io & Production of apricot \\
\hline $\mathbf{T}$ & 1 & -0.030 & 0.765 & 0.427 & 0.818 & -0.193 & -0.626 & -0.088 \\
\hline $\mathbf{P}$ & -0.030 & 1 & -0.341 & 0.437 & -0.418 & 0.663 & 0.388 & -0.826 \\
\hline $\mathbf{D f}$ & 0.765 & -0.341 & 1 & 0.186 & 0.672 & -0.258 & -0.536 & 0.203 \\
\hline $\mathbf{R}$ & 0.427 & 0.437 & 0.186 & 1 & 0.300 & 0.464 & 0.275 & -0.221 \\
\hline Itc & 0.818 & -0.418 & 0.672 & 0.300 & 1 & -0.439 & -0.600 & 0.136 \\
\hline Ic & -0.193 & 0.663 & -0.258 & 0.464 & -0.439 & 1 & 0.343 & -0.449 \\
\hline Io & -0.626 & 0.388 & -0.536 & 0.275 & -0.600 & 0.343 & 1 & -0.093 \\
\hline Production of apricot & $\mathbf{- 0 . 0 8 8}$ & $\mathbf{- 0 . 8 2 6}$ & $\mathbf{0 . 2 0 3}$ & $\mathbf{- 0 . 2 2 1}$ & $\mathbf{0 . 1 3 6}$ & $\mathbf{- 0 . 4 4 9}$ & $\mathbf{- 0 . 0 9 3}$ & $\mathbf{1}$ \\
\hline
\end{tabular}

The correlation matrix can be seen as the covariance matrix of the standardized random variables, table 3 shows the correlation matrix between the characters studied. Water deficit and compensated thermicity index were positively correlated to plant production. In this case, water deficithas a large influence on growth, development and productivity of plant. A high correlation was also observed between water deficit (0.203), compensated thermicity index conductivity (0.136), and apricot yield. That means the quality and yield of apricot were affected by the water deficit and compensated thermicity index more than other factors of the climatic and bioclimatic in Palestine. Herelies the importance of the soil where the apricots appropriate soil is deep mud good drainage and ventilation which is sensitive to salinity; also poor soil physicochemical characteristics are also high problem [39]. Biologically, most of limiting factors for its growing are evident such as blossoms killed by spring frosts, sudden (premature) wilting -apoplexy, winter killing of flower buds prior to bloom, Plum pox virus infection in apricot trees, absence of quality rootstock and modern growing technologies [40].

\subsection{Correspondence Analysis}

Correspondence analysis is performed on a contingency table. Also, correspondence analysis (CA) is a multivariate statistical technique proposed [41] by Hirschfeld [42] and later developed by Jean-Paul Benzécri [43]. It is conceptually similar to principal component analysis, but applies to categorical rather than continuous data, when we analyzed correspondence analysis is applied to each of the dependent variables and the seven physical parameters (independent variables), significant differences $(\mathrm{P}<0.05)$. These differences are lower in the case of apricots productions in Tulkarem and Hebron because the production is decreased.

In view of the linear correlation obtained, in this analysis was done by comparing the dependent variables apricots production with the total independent variables and the three bioclimatic parameters Io, Ic and It/Itc. In the first place it was observed that the Tulkarem, Salfit, Nablus and Ramallah type 
plots are located at the right of axis 1, with a proportion of the variance explained by axes $1(82.58 \%)$ and affected by the all climate and bioclimate factors, while the Hebron, Jerusalem, Bethlehem, Tubas, Jenin and Qalqilia types plots are located at the left of axes 1, with large a proportion of the variance explained by axes $1(82.58 \%)$ and axes $2(13.23 \%)$ (Fig.4).

However, We indicated that in the upper inframediterranean to mesomediterranean environments, the optimum for the production of apricot is achieved with value of annual ombrothermic index more than 2.5 , simple continentality index value between 14-22, compensated thermicity index value between 250-450, and the temperature between $20-24^{\circ} \mathrm{C}$ in Palestine.

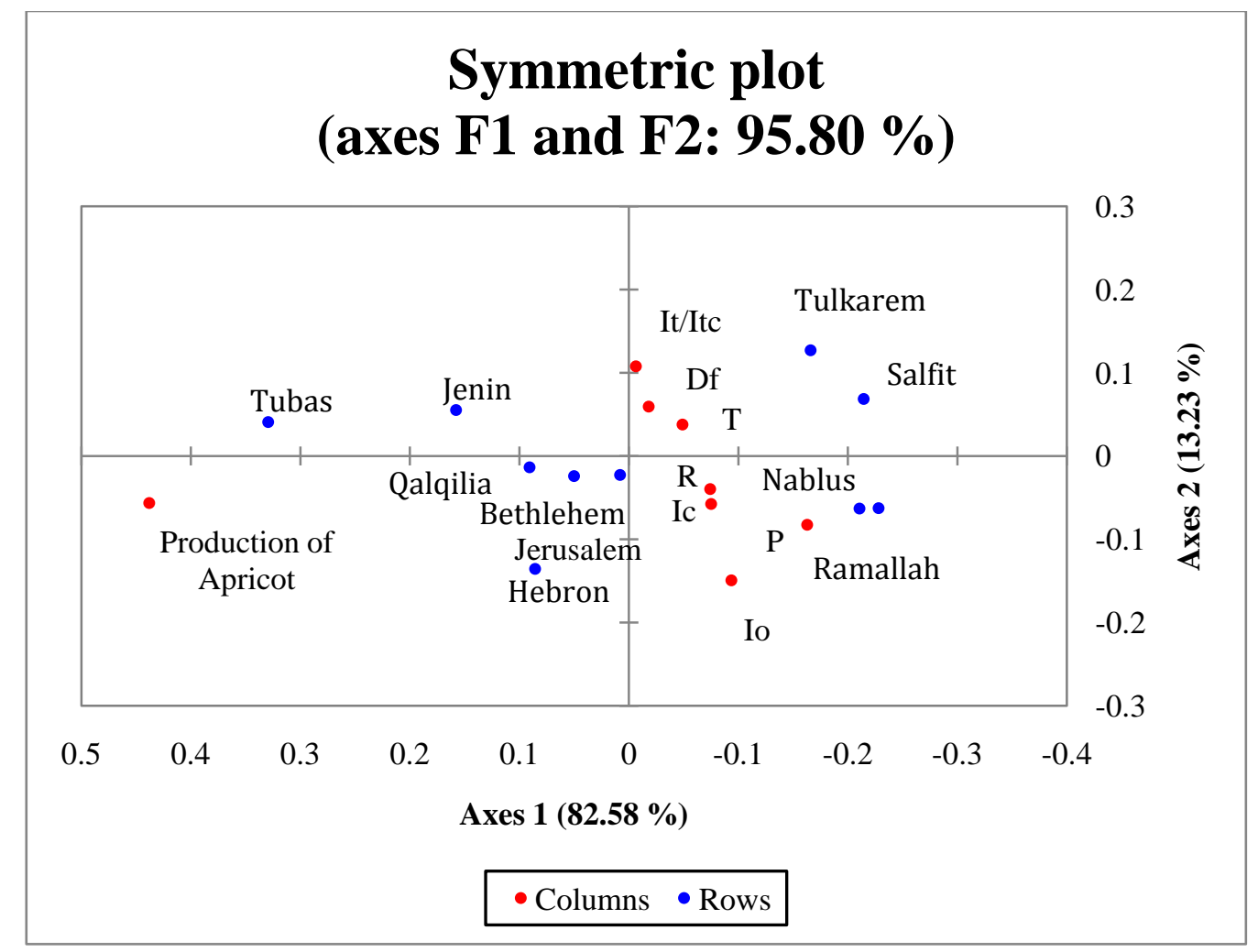

Fig4. Graphic Representation of Correspondence Analysis between the Apricot Production and Independent Variables

\section{CONCLuSiON}

Historically, the city of Hebron is one of most important of Palestinian territories to produce of apricots or nuts in general because of the climate appropriate for this but in recent, apricot production became in decline is due to the lack of rain, high temperatures, climate change, the spread of some diseases, such as fungal, and increase the settlement process by the Israeli occupation where there are more than 100 settlements as it is in the rest of the Palestinian territories occupied. Currently the apricot production in northern regions of Palestine over the middle and southern regions, especially in Tubas, Salfit and Jenin, therefore, we encouraged Apricot cultivation in these areas in addition to the Hebron area to increase the economy and maintaining food security in Palestine.

We indicated that apricot trees are affected by weather conditions, especially during the flowering period and modern decade as rising temperatures in the period after the contract and the growth of fruits adversely affect the yield and fruit specifications, in contrast, and the lack of cold during the fall and winter cause dormancy period is not complete and therefore lead to the delay in the open floral buds and vegetative, and biologically, apricot pollination is carried out by wind, bees and insects, which are attracted to the abundant blossoms produced during March and April and the fruits mature between June and July.

Moreover, in the infra mediterranean to mesomediterranean environments, the optimum for the production of apricot is achieved with value of annual ombrothermic index more than 2.5 , simple continentality index value between 14-22, compensated thermicity index value between 250-450, the temperature between $20-25^{\circ} \mathrm{C}$, with annual rainfall between $300-900$ millimeters, and with the dry to humid of ombrotype. 


\section{REFERENCES}

[1] Bortiri, E.; Oh, S.-H.; Jiang, J.; Baggett, S.; Granger, A.; Weeks, C.; Buckingham, M.; Potter, D.; Parfitt, D.E. "Phylogeny and systematics of Prunus (Rosaceae) as determined by sequence analysis of IT'S and the chloroplast trnL-trnF spacer DNA". Systematic Botany 26 (4): 797-807. JSTOR 3093861. (2001).

[2] De Poerderlé, M. le Baron. Manuel de l'Arboristeet du ForestierBelgiques: SecondeÉdition: Tome Premier. Brussels: Emmanuel Flon. p. 682. Downloadable Google Books. (1788).

[3] B. Arakelyan, "Excavations at Garni, " in Contributions to the Archaeology of Armenia, (Henry Field, ed.), Cambridge, 1968, page 29.(1949-50).

[4] Vavilov NI. Origin and geography of cultivated plants (tr. L. storr-best) Cambridge: CUP; (1992).

[5] Kostina KF. The use of varietal resources of apricots for breeding. TrudNikit Bot Sada; 40:4563. (1969).

[6] Faust M, Suranyl D, Nyujto F. Origin and dissemination of apricot. Hortic Rev; 22: 225-266. (1998).

[7] Hagen LS, Khadari B, Lambert P, Audergon JM. Genetic diversity in apricot revealed by AFLP markers: species and cultivars comparisons. TheorAppl Genet; 105:298-305. doi: 10.1007/ s00122-002-0910-8. (2002).

[8] Ercisli S., "Apricot culture in Turkey," Scientific Research and Essays, vol. 4, no. 8, pp. 715719, (2009)

[9] Quamme, H.A., Layne, R.E.C., Ronald, W.G. Relationship of super cooling to cold hardiness and the northern distribution of several cultivated and native Prunus species and hybrids. Can. J. Plant. Sci. 62, 137-148. (1982).

[10] Guerriero, R., Bartolini, S. Main factors influencing cropping behavior of some apricot cultivars in coastal areas. Acta Hort. 293, 229-243. (1991).

[11] FAOSTAT. Available at: http://faostat.fao.org. (2013).

[12] Ighbareyeh J. M. H., Cano-Ortiz, A. and Cano, E. Biological resources management in Palestine, Department of Animal and Plant Biology and Ecology, Faculty of Experimental Sciences, University of Jaen, Jaen, Spain, doctorate thesis, p 102-105. (2014).

[13] Ighbareyeh, J. M. H., A. Cano-Ortiz \& E. Cano. Biological and bioclimatic basis to optimize plant production: Increased economic areas of Palestine. Agricultural Science Research Journal 4(1); pp. 10- 20, 2014. Available online at http://www.resjournals.com/ARJ , ISSN: 2026 - 6332 (C)2014 International Research Journals. (2014).

[14] Ighbareyeh, J.M.H., Cano-Ortiz, A. and Cano, E. Case Study: Analysis of the Physical Factors of Palestinian Bioclimate. American Journal of Climate Change, 3, 223-231. http://dx.doi.org/ 10.4236/ajcc.2014.32021. (2014).

[15] Ighbareyeh, J. M. H., Cano-Ortiz, A., Suliemieh, A. A. A., Ighbareyeh, M. M. H. and Cano, E. Phytosociology with Other Characteristic Biologically and Ecologically of Plant in Palestine. American Journal of Plant Sciences, 5, 3104-3118. http://dx.doi.org/10.4236/ajps.2014. 520327. (2014).

[16] Ighbareyeh Jehad M. H., A. Cano-Ortiz, E. Cano Carmona, Mohammed M. H. Ighbareyeh, Asmaa A. A. Suliemieh. Study of Biology and Bioclimatology of Date Palm (Phoenix Dactylifera L.) To Optimize Yield and Increase Economic in Jericho and Gaza Cities of Palestine, International Journal of Research Studies in Biosciences (IJRSB) Volume 3, Issue1, January 2015, PP 1-8, ISSN 2349-0357 (Print) \& ISSN 2349-0365 (Online). www.arcjournals.org. (2015).

[17] Ighbareyeh, J. M. H., Cano-Ortiz, A., Suliemieh, A.A.A., Ighbareyeh, M. M. H. and Cano, E. Assessment of Biology and Bioclimatology of Plant to Increase Economic in Palestine. International Journal of Research Studies in Biosciences (IJRSB) Volume 3, Issue 3, March 2015, PP 1-8 ISSN 2349- 0357 (Print) \& ISSN 2349-0365, www.arcjournals.org. (2015).

[18] Ighbareyeh, J. M. H., Cano-Ortiz, A., Suliemieh, A. A. A., Ighbareyeh, M. M. H. and Cano, E. Biology and Bioclimatology Applied on Plant in Palestine, International Journal of Research 
Studies in Biosciences (IJRSB) Volume 3, Issue 3, March 2015, PP 79-86 ISSN 2349-0357 (Print) \& ISSN 2349-0365 (Online) www.arcjournals.org. (2015).

[19] Ighbareyeh, J.M.H., Cano-Ortiz, A., Suliemieh, A. A. A., Ighbareyeh, M.M.H. and Cano, E. Assessing Crop Yield Sustainability under the Climatic and Bioclimatic Change in the Area of Palestine. American Journal of Climate Change, 4, 48-56. http://www.scirp.org/journal/ ajcchttp://dx.doi.org/ 10.4236/ajcc.2015.41005. (2015).

[20] Ighbareyeh J. M. H., A. Cano-Ortiz, E. Cano Carmona, Mohammed M. H. Ighbareyeh, Asmaa A. A. Suliemieh. "Study Effect of Biology and Bioclimatology Applied on Plant in the Area of Hebron at the South of Palestine" has since been reviewed and it is accepted for publication in Volume 3, Issue 5, May 2015, PP 56-64, ISSN 2349-0357 (Print) \& ISSN 2349-0365. (2015).

[21] Ighbareyeh J. M. H., A. Cano-Ortiz, E. Cano Carmona, Mohammed M. H. Ighbareyeh, Asmaa A. A. Suliemieh. Effect of Biology and Bioclimatology Applied On Plant in the Area of Jenin at the North of Palestine, International Journal of Research Studies in Biosciences (IJRSB) Volume 3, Issue 6, June 2015, PP 1-6 ISSN 2349-0357 (Print) \& ISSN 2349-0365. (Online) www.arcjournals.org. (2015).

[22] Ighbareyeh Jehad M. H., A. Cano Ortiz, Eusebio Cano Ortiz, Mohamed M. H. Ighbareyeh and Asmaa A. A. Suliemieh. Study of climatology and bioclimatology applied on plant in area of Hebron in Palestine, International Multidisciplinary Research Journal, Volume - 5, Issue - 1, July - 2015, ISSN 2231-5063. (2015).

[23] Ighbareyeh J. M. H., A. Cano-Ortiz, E. Cano Carmona, Mohammed M. H. Ighbareyeh, Asmaa A. A. Suliemieh. Modeling of Biology and Bioclimatology Applied on Plant in Palestine. Swift Journal of Agricultural Research Vol 1(3) pp. 021-027 July, http://www.swiftjournals.org/sjar. (2015).

[24] Ighbareyeh J. M. H., A. Cano-Ortiz, E. Cano Carmona, Mohammed M. H. Ighbareyeh, Asmaa A. A. Suliemieh. Effect of Biology and Bioclimatology Applied Studies on Plant in the Area of Jerusalem in Palestine, International Journal of Research Studies in Biosciences (IJRSB), Volume 3, Issue 9, September 2015, PP 135-140, ISSN 2349-0357 (Print) \& ISSN 2349-0365 (Online) www.arcjournals.org. (2015).

[25] Cano E, Ruiz L, Cano-Ortiz. A Influencia de la Bioclimatología en la producción del olivar. Aldaba. 11: 151-155. (2001a).

[26] Ana Cano Ortiz, Jehad M.H. Ighbareyeh, Eusebio Cano. Bioclimatic Applications and Soil Indicators for Olive Cultivation (South of the Iberian Peninsula. Global Advanced Research Journal of Agricultural Science (ISSN: 2315-5094) Vol. 3(12) pp. 433-438, December, (2014).

[27] Rivas Martínez, S. Clasificación bioclimática de la Tierra. Folia Bot. Matritensis. 16:1-20. (1996).

[28] Rivas Martinez, S. Worldwide Bioclimatic Classification System. www.globalbioclimatics.org. (2004).

[29] Rivas-Martínez S., Rivas-Sáenz S., Penas A. Worldwide Bioclimatic Classification System. Global Geobotany vol. 1:1-634. (2011).

[30] Rivas-Martinez, S. Global bioclimatic, Internet: http://www.globalbioclimatics.org. (2008).

[31] Snedecor, G., Cochran, W. Statistical Methods. The Iowa State Univ. Press, Ames, IA, USA, 593 pp. (1968).

[32] Jarque, C., Bera, A. Efficient tests for normality homoscedasticity and serial independence of regression residuals. Econometric Letters 6, 255-259. (1980).

[33] Jarque, C., Bera, A. A test for normality of observations and regression residuals. International Statistical Review 55, 163-172. (1987).

[34] Shapiro, S., Wilk, M 1965. An analysis of variance test for normality (complete samples). Biometrika 52, 591-611. (1965).

[35] Shapiro, S., Wilk, M., Chen, H. A comparative study of various tests for normality. Journal of the American Statistical Association 63, 1343-1372. (1968).

[36] Gu, C., Li, C., Lu, L., Jiang, S., Alexander, C., Bartholomew, B., Brach, A.R., Boufford, D.E., Ikeda, H., Ohba, H., Robertson, K.R. and Spongberg, S.A. Flora of China. Volume 9: Rosaceae. Missouri Botanical Garden, St. Louis. (2003). 
[37] Tian-Ming, H., Xue-Sen, C., Zheng, X., Jiang-Sheng, G., Pei-Jun, L., Wen, L., Qing, L. and Yan, W. Using SSR markers to determine the population genetic structure of wild apricot (Prunusarmeniaca L.) in the Ily Valley of West China. Genetic Resources and Crop Evolution, 54: 563 - 572. (2007).

[38] Mengel, K., Kirkby, E.A., Kosegarten, H., Appel, T. Principles of Plant Nutrition, 5th ed. Kluwer Academic Publisher, Dordrecht, pp. 848. (2001).

[39] Milo`sevi'c, T., Milo`sevi'c, N. Response of young apricot trees to natural zeolite,organic and inorganic fertilisers. Plant Soil Environ. 59, 44-49. (2013).

[40] Milo`sevi'c, T., Milo`sevi'c, N., Gli`si'c, I., Kr`ska, B. Characteristics of promisingapricot (Prunusarmeniaca L.) genetic resources in Central Serbia based on blossoming period and fruit quality. Hortic. Sci. 37, 46-55. (2010).

[41] Dodge, Y. The Oxford Dictionary of Statistical Terms, OUP ISBN 0-19-850994-4. (2003).

[42] Hirschfeld, H.O. "A connection between correlation and contingency", Proc. Cambridge Philosophical Society, 31, 520-524. (1935).

[43] Benzécri, J.-P. L'Analyse des Données. Volume II. L'Analyse des Correspondances. Paris, France: Dunod. (1973). 